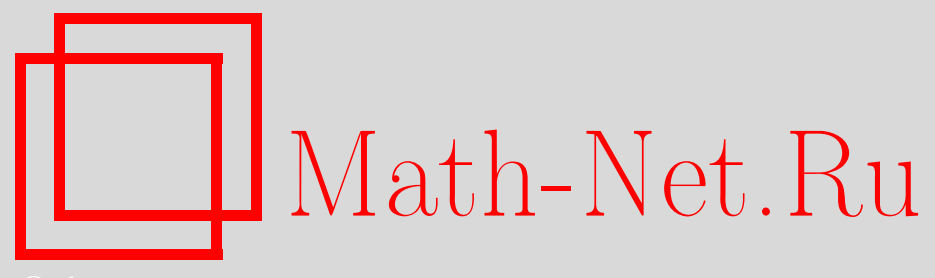

С. Варламов, Поверхностное натяжение и температура, Квант, 2019, номер 6, 8-10

DOI: https://doi.org/10.4213/kvant20190602

Использование Общероссийского математического портала Math-Net.Ru подразумевает, что вы прочитали и согласны с пользовательским соглашением http://www.mathnet.ru/rus/agreement

Параметры загрузки:

IP: 18.234 .197 .8

26 апреля 2023 г., 15:42:31

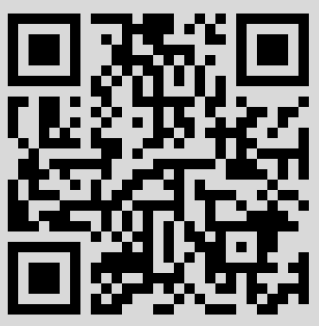




\section{Поверхностное натяжение и температура}

\section{С.ВАРЛАМОВ}

А РИСУНКЕ 1, ВЗЯТОМ ИЗ СПРАВОЧ- ника «Физические величины» (под редакцией И.С.Григорьева и Е.З.Мейлихова), видно, что зависимости коэффициентов поверхностного натяжения $\sigma$ для раз-

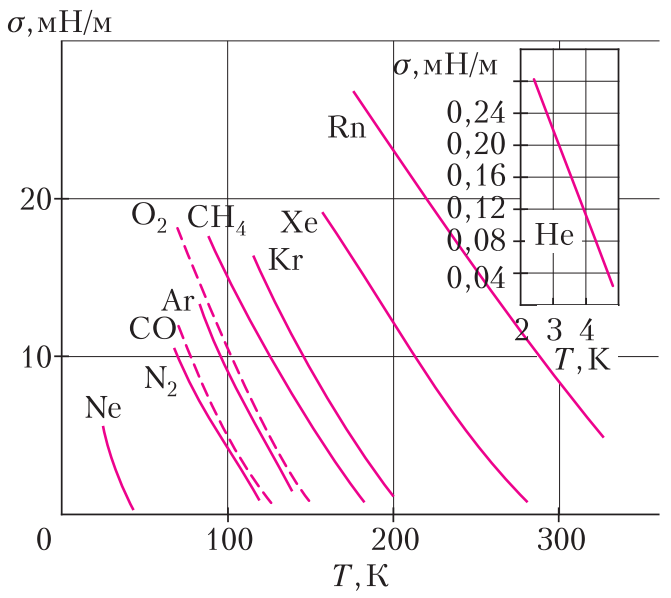

Pnc. 1

ных сжиженных газов выглядят похожим образом - они весьма близки к линейным. Диапазон температур, в котором существует жидкое состояние вещества, для каждого вещества определяется двумя точками: температурой плавления (а точнее, температурой тройной точки) и критической температурой. Пользуясь моделью взаимодействия молекул, размеры которых $D$, можно дать объяснение этим зависимостям. Суть в том, что у молекул, находящихся на поверхности раздела конденсированной и газообразной фаз вещества, усредненное число $Z_{\text {пов }}$ ближайших соседок, каждая из которых обеспечивает молекуле на поверхности вклад в глубину

DOI: https://doi.org/10.4213/kvant20190602 потенциальной ямы $U_{0}$, меньше соответствующего числа $Z_{\text {внутр }}$ соседок у молекул, находящихся внутри конденсированной фазы. С ростом температуры плотность газообразной фазы растет, а плотность конденсированной фазы убывает, и это соответствует уменьшению разницы $\left(Z_{\text {внутр }}-Z_{\text {пов }}\right)$. В результате микроскопическая поверхностная энергия, приходящаяся на площадку с размерами порядка размеров одной молекулы ( $\left.S \approx D^{2}\right)$ и равная

$$
\sigma=\frac{U_{0}\left(Z_{\text {внутр }}-Z_{\text {пов }}\right)}{D^{2}},
$$

убывает с ростом температуры.

При низких температурах поверхность жидкости почти плоская, это похоже на поверхность моря в отсутствие ветра (рис.2, слева). А если температура высокая, то поверхность получается «развитая» - как поверхность моря, покрытая волнами (рис.2, справа). Чем выше температура, тем больше получается реальная площадь поверхности раздела «жидкость-пар» при том же самом «теоретическом» периметре этой поверхности. Этот образ - поверхность моря с волнами - позволяет понять, почему для увеличения поверхности на $\Delta S$ нужна дополнительно к работе внешних сил теплота и почему с ростом температуры уменьшается коэффициент поверхностного натяжения.

Законно поставить вопрос: а каков вклад во внутреннюю энергию жидкости участка ее поверхности, который имеет площадь $S_{0}$ (плоская поверхность, ограниченная периметром), и как этот вклад зависит от температуры?

Если рассматривать поверхностный слой молекул как промежуточную фазу веще- 


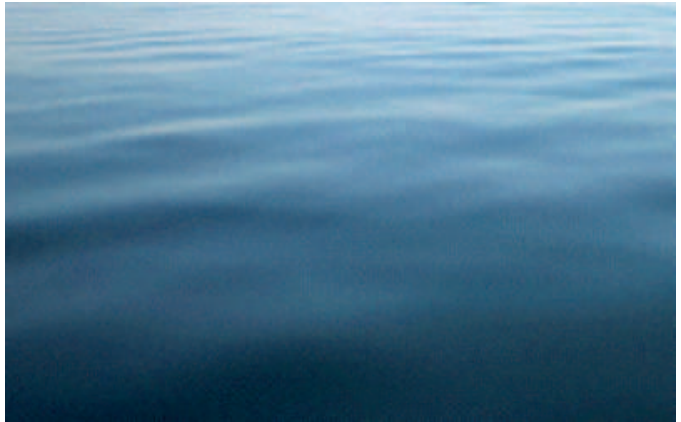

Puc. 2

ства (между конденсированным и газообразным состоянием), то для перевода молекул из конденсированной фазы в эту промежуточную фазу нужно сообщить им дополнительную тепловую энергию и при этом внешние силы должны совершить механическую работу. В результате внутренняя энергия увеличивается. Ситуация здесь аналогична переходу вещества из конденсированного состояния в газообразное. Отличаются только знаки работ внешних сил. При испарении вещества внешние силы (силы давления снаружи) совершают отрицательную работу, а при увеличении площади поверхности жидкости внешние силы совершают положительную работу. Собственно, именно поэтому давление насыщенных паров растет с ростом температуры, а коэффициент поверхностного натяжения уменьшается.

Если считать, что на проведенной (мысленно) границе, выделяющей участок поверхности жидкости $S_{0}$, поверхность жидкости колеблется, то среднее значение косинуса угла $\alpha$ между реальной поверхностью жидкости и плоской поверхностью $S_{0}$, натянутой (мысленно) на границу, вместе с микроскопической величиной поверхностной энергии $\sigma$, приходящейся на единицу площади, определяют проекцию силы натяжения прямого участка границы длиной $\Delta L_{0}$ на плоскую поверхность: $\sigma \Delta L_{0} \cos \alpha$. С другой стороны, если мысленно провести к «средней» по времени плоскости поверхности жидкости перпендикулярно ей плоскость и зафиксировать длину отрезка пересечения (части периметра), то при выделенном мысленно «прямом» отрезке периметра «реальная» дли-

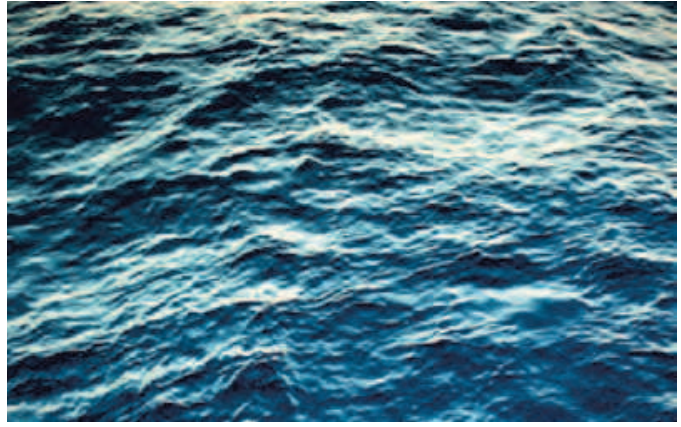

на границы раздела за счет волнистости поверхности будет больше. Если угол между «прямым» участком границы и реальным равен $\beta$, то реальная длина участка поверхности стала больше: $\Delta L_{0} / \cos \beta$. И вместе эти два фактора в среднем по времени должны компенсировать друг друга. Так как средние значения углов наклона $\alpha$ и $\beta$, очевидно, одинаковые, то усредненное значение проекции силы на плоскую поверхность будет равно

$$
\sigma \Delta L_{0} \frac{\cos \alpha}{\cos \beta} \approx \sigma \Delta L_{0},
$$

где $\sigma$ - величина коэффициента поверхностного натяжения, приводимая в справочнике.

Внешние силы при увеличении площади поверхности жидкости на $S_{0}$ совершают работу

$$
A=\sigma S_{0} .
$$

При этом дополнительная тепловая энергия $Q$, нужная для того, чтобы при увеличении площади «плоской» поверхности на $S_{0}$ сохранилась температура жидкости, на самом деле идет на то, чтобы создалась дополнительная бо́льшая площадь поверхности. Измеренная суммированием по всем микроскопическим изгибам поверхности площадь может быть в несколько раз больше площади поверхности: $S_{0} \rightarrow S=S_{0} k$, где $k>1$. В итоге закон сохранения энергии $Q+A=\Delta U$ дает такое соотношение:

$$
Q+S_{0} \sigma=\left(S_{0} k\right) \sigma \text {, или } Q=S_{0} \sigma(k-1) \text {. }
$$

Коэффициент поверхностного натяжения (данные справочника) изменяется с температурой линейно. Эту зависимость 
можно описать формулой

$$
\sigma_{T}=\sigma_{T_{0}} \frac{T_{\text {крит }}-T}{T_{\text {крит }}-T_{0}} .
$$

Здесь $\sigma_{T_{0}}-$ коэффициент поверхностного натяжения при некоторой температуре $T_{0}$, а $T$ - текущая температура. Если устроить тепловой двигатель, работающий по циклу Карно с нагревателем и холодильником, имеющими близкие температуры $T+\Delta T$ и $T$, в котором в качестве рабочего тела будет выступать пленка поверхности жидкости, то КПД такого двигателя будет равен $\Delta t / T$ и можно написать такое соотношение:

$$
S_{0} \Delta \sigma=Q \frac{\Delta t}{T},
$$

или

$S_{0} \sigma_{T_{0}} \frac{\Delta t}{T_{\text {крит }}-T_{0}}=S_{0} \sigma_{T_{0}} \frac{T_{\text {крит }}-T}{T_{\text {крит }}-T_{0}}(k-1) \frac{\Delta t}{T}$.

Сократив на одинаковые множители, получаем

$$
1=\frac{T_{\text {крит }}-T}{T}(k-1) \text {, или } k-1=\frac{T}{T_{\text {крит }}-T} \text {. }
$$

Подставим полученное выражение в формулу для $Q$ :

$$
Q=S_{0} \sigma_{T} \frac{T}{T_{\text {крит }}-T} .
$$

Если добавить к этой энергии работу вне- шних сил, то получится вклад во внутреннюю энергию жидкости при температуре $T$ ее поверхности величиной $S_{0}$ (плоская поверхность с заданным периметром):

$$
\Delta U=Q+A=S_{0} \sigma_{T} \frac{T_{\text {крит }}}{T_{\text {крит }}-T} .
$$

Ответ на поставленный вопрос получен.

Как видно из формулы для $\Delta U$, в знаменателе стоит разность температур, которая при приближении $T$ к $T_{\text {крит }}$ стремится к нулю. Но и сам коэффициент $\sigma_{T}$ тоже стремится к нулю. Подставим в формулу значение $\sigma_{T}$, выраженное через значение при некоторой температуре $T_{0}$ :

$$
\Delta U=Q+A=S_{0} \sigma_{T_{0}} \frac{T_{\text {крит }}}{T_{\text {крит }}-T_{0}} .
$$

Получилась удивительная вещь: добавок внутренней энергии, связанный с наличием свободной поверхности, не зависит от температуры!

Имеется отдаленная аналогия с известной задачей о запасе энергии теплового движения воздуха в комнате при разных температурах воздуха, но при фиксированном давлении. И там тоже запас энергии не зависит от температуры, а определяется только давлением воздуха и объемом комнаты.

\section{«КВАНТ» ДЛЯ МЛАДШИХ ШКОЛЬНИКОВ}

\section{Что не так с перестановкой слагаемых?}

\section{$K . K O X A C b$}

ДРАВСТВУЙТЕ, УВАЖАЕМЫЕ ТЕлезрители! Незаметно прошла неделя, и вы смотрите очередной потрясающий выпуск научно-популярной телепере-

DOI: https://doi.org/10.4213/kvant20190603 дачи «Что не так?» Меня зовут Горгулий, в нашей передаче мы не боимся прямо и честно рассказывать о самых замысловатых сюжетах. Задавайте нам свои вопросы прямо на сайте телепередачи. Тема сегодняшнего выпуска, как обычно, предложена телезрителями. 